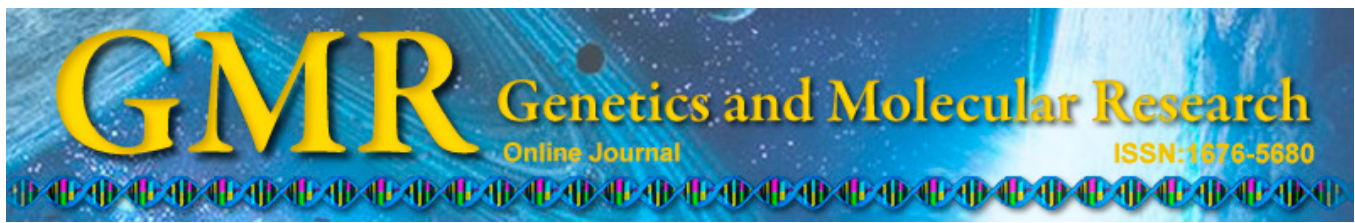

\title{
Single nucleotide polymorphism analysis of the endopolygalacturonase gene in peach and its potential use in crossbreeding programs
}

\author{
Y. Jiao, R. Ma and M. Yu \\ Institute of Horticulture, Jiangsu Academy of Agricultural Sciences/ \\ Jiangsu Key Laboratory for Horticultural Crop Genetic Improvement, \\ Nanjing, Jiangsu, China
}

Corresponding author: $\mathrm{M}$. Yu

E-mail: mly1008@aliyun.com

Genet. Mol. Res. 14 (2): 4090-4101 (2015)

Received November 25, 2014

Accepted March 24, 2015

Published April 27, 2015

DOI http://dx.doi.org/10.4238/2015.April.27.24

\begin{abstract}
Single nucleotide polymorphisms (SNPs) are the most abundant sequence variations found in plant genomes and are widely used as molecular genetic markers in genetic diversity studies and crossbreeding programs. In this study, we examined 113 DNA sequences of the endopolygalacturonase (endo- $P G$ ) gene from 67 peach accessions and found a total of 56 SNPs and 6 insertion/ deletions (indels), with a frequency of 3,1 , and $3 \%$ for the transitions, transversions, and indels, respectively. Meanwhile, the majority of the observed SNPs were found in the intron regions, while only 2 variable sites and a single indel were detected in the exon regions. A dendrogram was obtained using neighbor-joining cluster analysis and divided into 2 main groups, providing evidence that most of the accessions of the clingstone nonmelting flesh phenotypes generally clustered together and were comparatively nonrelated to the "stony hard" peach cultivars, which were in a different branch altogether. Furthermore, 4 major haplotypes were formed and 3 cleaved amplified polymorphic sequence primer sets were mined according to fruit texture and stone adhesion, displaying their potential as candidate molecular markers
\end{abstract}


for discriminating genotypes. This research will assist peach genetic enhancement by introducing a novel crossbreeding strategy.

Key words: Single nucleotide polymorphism; endo- $P G$ gene; Haplotype; Insertion/deletions (indels);

Cleaved amplified polymorphic sequence (CAPS)

\section{INTRODUCTION}

Single nucleotide polymorphisms (SNPs) are widely used as molecular genetic markers in genetic linkage mapping (Martinez-Garcia et al., 2013), diversity analysis (Emanuelli et al., 2013), cultivar identification (Eduardo et al., 2013), and marker-assisted selection (MAS) (Verde et al., 2012). Recent studies of the peach have shown that SNPs are distributed at a frequency of one SNP for every $598 \mathrm{bp}$, one indel for every $4189 \mathrm{bp}$; moreover, variability is $\sim 6$-fold higher in noncoding regions when compared to coding regions (one SNP for every $390 \mathrm{bp}$ in noncoding DNA vs one for every $1850 \mathrm{bp}$ in coding DNA) (Aranzana et al., 2012). Additionally, a 9K SNP array distributed over all 8 peach chromosomes, with an average spacing of $26.7 \mathrm{~kb}$ between SNPs, was recently developed (Verde et al., 2012), which can be used worldwide for genetic studies.

In the peach, Prunus persica (L.) Batsch, flesh firmness is considered a quantitative trait that is affected by several biochemical and physiological factors, such as differences in the levels of apoplastic $\mathrm{Ca}^{2+}$, changes in cell wall architecture, and more (Fischer and Bennett, 1991; Morgutti et al., 2006). Based on previous research, many enzymes play a role in cell wall degradation. In particular, endopolygalacturonase (endo-PG, EC 3.2.1.15) is an enzyme involved in the depolymerization of pectin, a major component of cell walls that is extensively disassembled during the late stages of fruit softening (Hayama et al., 2003, 2006a,b; Tatsuki et al., 2013). On this same note, the lack of a melting phase in nonmelting flesh (NMF) genotypes has been shown to be caused by a deletion of the endo- $P G$ genes or a truncation of their mRNAs, which, in turn, causes an absence of the immunodetectable endo-PG protein (Lester et al., 1994; Brummell et al., 2004). These data indicate that endo$P G$-mediated pectin modification may play an important role in the later stages of softening and textural changes during the ripening of the peach. Therefore, an integrative analysis of the structure and its relation to the texture of the peach will play a significant role in improving its genetic characteristics.

At present, published studies have mainly focused on analyzing the activities and gene expression of endo-PG (Lester et al., 1994; Ma et al., 1999; Hayama et al., 2003; Brummell et al., 2004; Tatsuki et al., 2013); only a few studies have yet to analyze SNPs (Hayama et al., 2006a). In one of these studies, the selected fragments of an endo- $P G$ gene (1172 bp) from the genomic DNA isolated from 2 peach cultivars were subsequently amplified, cloned, and sequenced, showing 31 SNPs, 2 main deletions of 17 bp each, a 2-bp deletion, and a 2-bp insertion (Morgutti et al., 2006). Thus, it can be concluded that the endo- $P G$ gene has a high level of genetic diversity. In general, the key to analyzing the endo- $P G$ gene lays in the development of trait-associated markers to identify polymorphisms, which may also be useful for predicting the phenotype of a fruit. The cleaved amplified polymorphic sequence (CAPS) method has made it possible to develop reliable and rapid PCR-based markers (Konieczny and Ausubel, 1993; Komori and Nitta, 2005). 
Although the previous study provided evidence that the traits of fruit texture and stone adhesion were closely associated with the endo- $P G$ gene, without absolute agreement between the DNA profile and other special types, such as the "stony hard" peach that was characterized by a firm flesh in mature fruit, doubts about the authenticity of these data will remain. In this study, we plan to identify SNPs within peach accessions from partial DNA in endo- $P G$ sequences; the primary aims were to discriminate peach cultivars and assess their genetic diversity. This study should provide the basis for early MAS of flesh texture.

\section{MATERIAL AND METHODS}

\section{Plant materials and DNA extraction}

Sixty-seven peach accessions were used in this experiment (Table 1). The genomic DNA was extracted from young leaves by the optimized CTAB method as previously described (Manubens et al., 1999), and the concentration was measured spectrophotometrically at $260 \mathrm{~nm}$. The purified DNA was adjusted to a working solution of $40 \mathrm{ng} / \mu \mathrm{L}$.

\section{Cloning and sequencing}

DNA was used as a template for amplification with the primers (forward: 5'-AGGC GTTGCTTGTGGACCTG-3'; reverse: 5'-CTCGCTGCAAGGGTGCTTGGGAC-3'), according to the partial genomic sequence of the peach endo- $P G \mathrm{AC} 1$ clone (GenBank accession No. AY262754.1). Each 25- $\mu \mathrm{L}$ reaction mixture contained 10X PCR buffer (plus $\mathrm{Mg}^{2+}$ ), $0.2 \mathrm{mM}$ of each dNTP, $0.25 \mu \mathrm{M}$ of each primer, and $0.5 \mathrm{U}$ rTaq polymerase (TaKaRa, Nanjing, China) in addition to $40 \mathrm{ng}$ genomic DNA template. Amplification was performed in an Eppendorf Mastercycler (Germany), programmed for initial denaturation at $94^{\circ} \mathrm{C}$ for 5 min; followed by 34 cycles at $94^{\circ} \mathrm{C}$ for $40 \mathrm{~s}, 30 \mathrm{~s}$ at $58^{\circ} \mathrm{C}$ for $40 \mathrm{~s}, 2 \mathrm{~min}$ at $72^{\circ} \mathrm{C}$; and a final extension step of $10 \mathrm{~min}$ at $72^{\circ} \mathrm{C}$. Moreover, each PCR product was run on a $2 \%$ agarose gel at $110 \mathrm{~V}$ in order to check the quality, and the fragments were recovered from the gels. PCR amplification products that yielded single, well-defined bands were chosen and purified using the QIAquick PCR Purification Kit (Qiagen, China). The amplified fragment was inserted into a pMD19-T vector (TaKaRa), which was obtained by subcloning the fragment into Escherichia coli DH5a (BioTeKe Corporation, China) and sequenced by the Invitrogen Company (Shanghai, China).

\section{Genotyping}

DNA was used as a template for amplification with the primer (Table 2) at an annealing temperature of $50^{\circ} \mathrm{C}$. PCR amplification products were purified (as above) and restriction endonuclease digestions were conducted using the restriction enzymes $H p y \mathrm{CH} 4 \mathrm{~V}$ (NEB, Shanghai) and MaeIII (Roche, Germany). The restriction enzyme (HpyCH4V) mix (20 $\mu \mathrm{L})$, containing $2.5 \mu \mathrm{L}$ restriction enzyme buffer, $2.5 \mathrm{U}$ enzyme, and $500 \mathrm{ng}$ DNA template was added to each tube and incubated for $15 \mathrm{~min}$ at $37^{\circ} \mathrm{C}$ before inactivation at $65^{\circ} \mathrm{C}$ for $20 \mathrm{~min}$. The restriction enzyme (MaeIII) mix $(25 \mu \mathrm{L})$, containing $12.5 \mu \mathrm{L}$ restriction enzyme buffer, $1.0 \mathrm{U}$ enzyme, and $500 \mathrm{ng}$ DNA template, was added to each tube and incubated for $80 \mathrm{~min}$ at $55^{\circ} \mathrm{C}$. Fragments were then separated on $3 \%(\mathrm{w} / \mathrm{v})$ agarose gels. 
Table 1. List of the 67 accessions used in this study.

\begin{tabular}{|c|c|c|c|c|}
\hline No. & Accession & Texture & Stone adhesion & Origin \\
\hline 1 & Zaomei & Melting & Clingstone & Beijing, China \\
\hline 2 & Xuebaitao & Melting & Clingstone & Changli, Hebei, China \\
\hline 3 & Piqiutao & Melting & Clingstone & Chengdu, Sichuan, China \\
\hline 4 & Hongganlu & Melting & Clingstone & Dalian, Liaoning, China \\
\hline 5 & Fenghuayulu (early) & Melting & Clingstone & Fenghua, Zhejiang, China \\
\hline 6 & Fenghuayulu (late) & Melting & Clingstone & Fenghua, Zhejiang, China \\
\hline 7 & Huayulu & Melting & Clingstone & Fenghua, Zhejiang, China \\
\hline 8 & Fenghuapantao & Melting & Clingstone & Fenghua, Zhejiang, China \\
\hline 9 & Zaofengwang & Melting & Clingstone & Guan, Hebei, China \\
\hline 10 & Jianayan & Melting & Clingstone & Japan \\
\hline 11 & Kurakatowase & Melting & Clingstone & Japan \\
\hline 12 & Hakubo & Melting & Clingstone & Japan \\
\hline 13 & Beni Hakuto & Melting & Clingstone & Japan \\
\hline 14 & Huiyulu & Melting & Clingstone & Nanjing, Jiangsu, China \\
\hline 15 & Xiahui 5 & Melting & Clingstone & Nanjing, Jiangsu, China \\
\hline 16 & Xiahui 6 & Melting & Clingstone & Nanjing, Jiangsu, China \\
\hline 17 & Xiahui 8 & Melting & Clingstone & Nanjing, Jiangsu, China \\
\hline 18 & Baimipantao & Melting & Clingstone & Nanjing, Jiangsu, China \\
\hline 19 & Baimangpantao & Melting & Clingstone & Shanghai, China \\
\hline 20 & Galaxy & Melting & Clingstone & USA \\
\hline 21 & Mayfire & Melting & Clingstone & USA \\
\hline 22 & Florldacreat & Melting & Clingstone & USA \\
\hline 23 & Armking & Melting & Clingstone & USA \\
\hline 24 & Florldaking & Melting & Clingstone & USA \\
\hline 25 & Baihuashuimi & Melting & Clingstone & Wuxi, Jiangsu, China \\
\hline 26 & Xuanchengtiantao & Melting & Clingstone & Xuancheng, Anhui, China \\
\hline 27 & Yangzhouzaotiantao & Melting & Clingstone & Yangzhou, Jiangsu, China \\
\hline 28 & Yixianbai & Melting & Freestone & Beijing, China \\
\hline 29 & Jingyu & Melting & Freestone & Beijing, China \\
\hline 30 & Beijingyixianhong & Melting & Freestone & Beijing, China \\
\hline 31 & Diaozhibai & Melting & Freestone & Bozhou, Anhui, China \\
\hline 32 & Heiyoutao & Melting & Freestone & Jiangsu, China \\
\hline 33 & Nanjingbaisha & Melting & Freestone & Jiangsu, China \\
\hline 34 & Banjintao & Melting & Freestone & Guanyang, Guangxi, China \\
\hline 35 & Zaoxialu & Melting & Freestone & Hangzhou, Zhejiang, China \\
\hline 36 & Fertini Morettini & Melting & Freestone & Italy \\
\hline 37 & Okubo & Melting & Freestone & Japan \\
\hline 38 & Sunago Wase & Melting & Freestone & Japan \\
\hline 39 & Hakoromo & Melting & Freestone & Japan \\
\hline 40 & Baopiyangtao & Melting & Freestone & Japan \\
\hline 41 & Yejihong & Melting & Freestone & Jurong, Jiangsu, China \\
\hline 42 & Kashiliguang & Melting & Freestone & Kashi, Xinjiang, China \\
\hline 43 & Shuibaitao & Melting & Freestone & Nanjing, Jiangsu, China \\
\hline 44 & Huozhu & Melting & Freestone & Nanjing, Jiangsu, China \\
\hline 45 & Yuhualu & Melting & Freestone & Nanjing, Jiangsu, China \\
\hline 46 & Zaoshanghaishuimi & Melting & Freestone & Nanjing, Jiangsu, China \\
\hline 47 & Chunlei & Melting & Freestone & Shanghai, China \\
\hline 48 & Nanshantiantao & Melting & Freestone & Shenzhen, Guangdong, China \\
\hline 49 & Early Red 2 & Melting & Freestone & USA \\
\hline 50 & Fantasia & Melting & Freestone & USA \\
\hline 51 & Lulin & Melting & Freestone & Yixing, Jiangsu, China \\
\hline 52 & Wuyuexianbiangan & Non-melting & Clingstone & Beijing, China \\
\hline 53 & Yanwohong & Non-melting & Clingstone & Heibei, China \\
\hline 54 & Myojyo & Non-melting & Clingstone & Japan \\
\hline 55 & Yinxing & Non-melting & Clingstone & Japan \\
\hline 56 & Roupantao & Non-melting & Clingstone & Jinta, Gansu, China \\
\hline 57 & Yumyeoung & Non-melting & Clingstone & Korea \\
\hline 58 & Jinxu & Non-melting & Clingstone & Nanjing, Jiangsu, China \\
\hline 59 & Jinhui & Non-melting & Clingstone & Nanjing, Jiangsu, China \\
\hline 60 & Xiacui & Non-melting & Clingstone & Nanjing, Jiangsu, China \\
\hline 61 & Phillips & Non-melting & Clingstone & USÄ \\
\hline 62 & Troubador & Non-melting & Clingstone & USA \\
\hline 63 & Babygold 6 & Non-melting & Clingstone & USA \\
\hline 64 & Huayu & Non-melting & Clingstone & Beijing, China \\
\hline 65 & Oro A* & Non-melting & Clingstone & - \\
\hline 66 & Bolero* & Melting & Freestone & - \\
\hline 67 & Suncrest* & Melting & Freestone & USA \\
\hline
\end{tabular}

*DNA sequences of OroA, Bolero, and Suncrest were downloaded from NCBI and corresponded to accession Nos. DQ659240.1, DQ659241.1, and AY262754.1, respectively. 


\section{Statistical analysis}

The obtained sequences were analyzed and assembled using the SeqMan contig assembler from the DNASTAR package. A phylogenetic tree was constructed based on nucleic acid sequences via the neighbor-joining (NJ) method using MEGA5.05 (Tamura et al., 2011). Both sequence alignment and annotation were performed using the GeneDoc software (Version 2.7.000, NRBSC, USA). DnaSP 5.0 was employed to calculate the nucleotide diversity $(\mathrm{Pi})$, the average number of nucleotide differences $(K)$, and identify haplotypes.

\section{RESULTS}

\section{Analysis of base changes}

In this study, 113 high-quality sequences were obtained for analysis of the SNPs in the endo- $P G$ gene. DnaSP analysis indicated that the selected region (1-1174) of 113 sequences had 1133 sites (excluding the sites with gaps). There were 1077 invariable (monomorphic) sites and 56 variable (polymorphic) sites, including 6 singleton variable sites and 50 parsimony informative sites. Of the variable sites, all had at least 2 variants. Furthermore, 48 of the 50 parsimony sites contained 2 variants, while the other 2 sites had 3 variants. Fifty-six SNPs (not including indels) and 39 transitions were identified, including $19 \mathrm{C} / \mathrm{T}$ and $20 \mathrm{~A} / \mathrm{G}$. Meanwhile, 17 transversions were also detected, containing $5 \mathrm{~A} / \mathrm{T}, 6$ $\mathrm{A} / \mathrm{C}, 4 \mathrm{~T} / \mathrm{G}$, and $3 \mathrm{C} / \mathrm{G}$; transition mutations were notably more common than transversion mutations as the ratio was approximately 2.29:1. Moreover, variants from $\mathrm{SNP}_{857.858}$ were rare, concomitantly involving both transitions and transversions (Figure 1); the exact cause was unknown. The $P i$ and average $K$ for all sequences were 0.02 and 21.48, respectively. Subsequently, 44 accessions were shown to have 2 different alleles, indicating that the heterozygosity of the endo- $P G$ gene was high.

In addition, as identified by multiple-sequence alignment, only 2 variable sites (at positions 348 and 353; Figure 1) and one indel (at position 1159) were detected in the exon regions. Of these, 2 of the detected SNPs were nonsynonymous from the different melting or nonmelting peach cultivars, and the indel (at position 115) was unique (i.e., only present in one accession, 'Baihuashuimi'). This result indicates that the exon regions have a significantly lower level of nucleotide diversity relative to that of the intron regions.

\section{Haplotypes and analysis of insertions/deletions}

Thirty-two haplotypes were identified in this study. Among these haplotypes, 4 haplotypes were the most common (named HAP1, HAP2, HAP3, and HAP4), and the rest of the haplotypes were unique (i.e., present in 1-2 accessions). Among these haplotypes, there were 17 accessions in both HAP1 and HAP2, while only 5 accessions belonged to the HAP 3 group. HAP4 was the most common haplotype and included a total of 23 accessions (Table 2). Significantly, there were 3 accessions in HAP4 that contained 2 haplotypes, indicating that they have a complicated genetic background. 


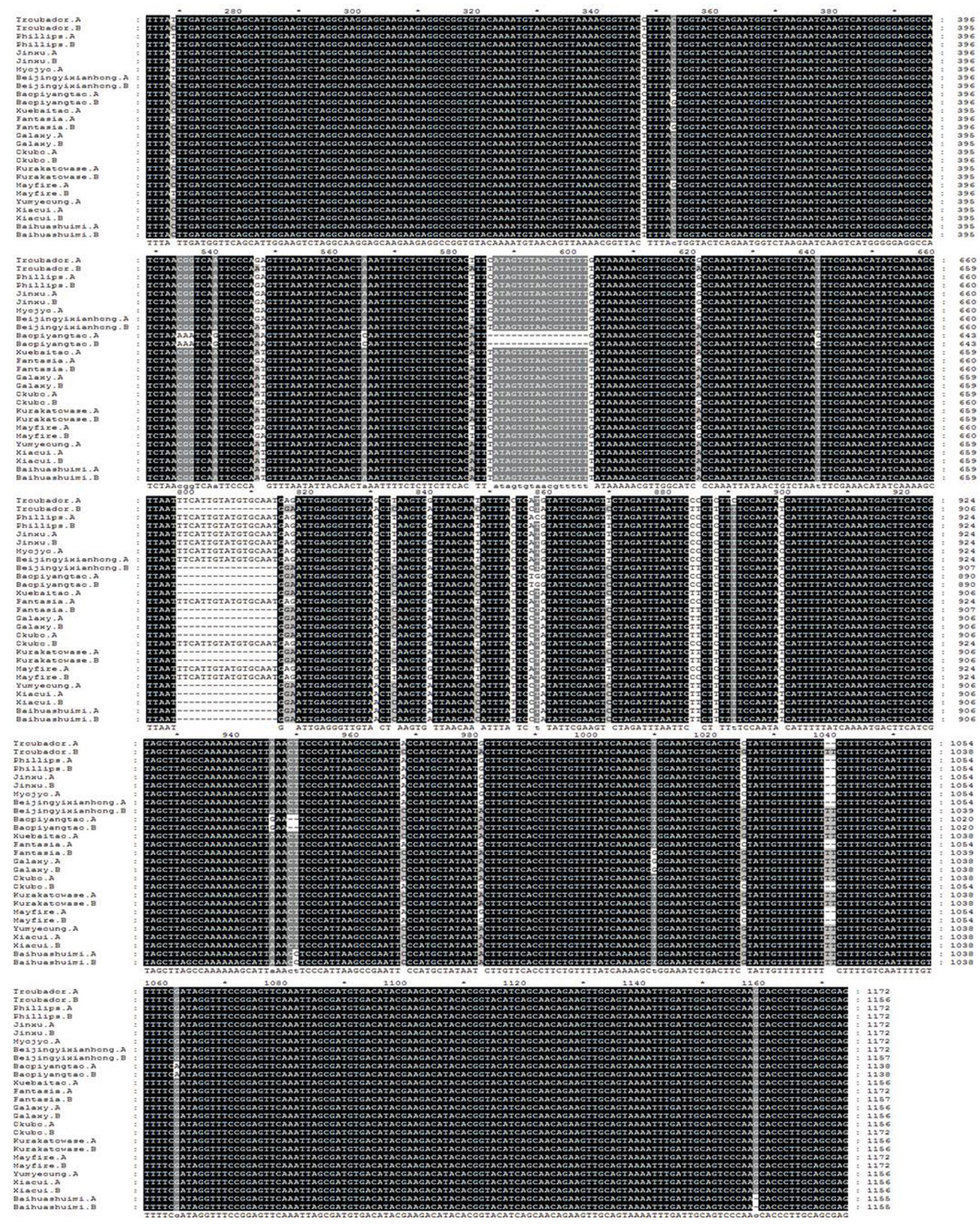

Figure 1. Comparison of selected DNA fragments of the peach (Prunus persica) endopolygalacturonase (endo-PG) from nonmelting flesh (NMF) cultivars 'Troubador', 'Phillips', 'Jinxu', and 'Myojyo', and the stony hard peach cultivars 'Xiacui' and 'Yumyeoung'; the other varieties were melting flesh (MF) cultivars. 
Table 2. Main haplotype patterns from the 67 accessions used in this study.

\begin{tabular}{|c|c|}
\hline Haplotype & Accessions \\
\hline HAP1 & $\begin{array}{l}\text { Piqiutao. Lulin. Early Red 2. Jinhui. Mayfire. 99.34-13. Okubo. Phillips. Zaoshanghaishuimi. Babygold 6. Jinxu. Yinxing. } \\
\text { Roupantao. Fantasia. Yejihong. Yixianbai. Oro A }\end{array}$ \\
\hline HAP2 & $\begin{array}{l}\text { Nanjingbaisha. Yuhualu. Jingyu. Kashiliguang. Nanshantiantao. Zaomei. Sunago Wase. Florldaking. Zaoshanghaishuimi. } \\
\text { Fertini Morettini Zaoxialu. Hakoromo. Armking. Diaozhibai. Baopiyangtao. Heiyoutao. Bolero }\end{array}$ \\
\hline HAP3 & Xuanchengtiantao. Wuyuexianbiangan. Yanwohong. Diaozhibai. Xuebaitao \\
\hline HAP4 & $\begin{array}{l}\text { Huayu. Piqiutao. Fenghuayulu (late). Huiyulu. Xiahui 5. Xiahui 6. Zaohualu. Yumyeoung. Xiahui 8. Fenghuayulu (early). } \\
\text { Jianayan. Okubo. Baimangpantao. Hongganlu. Kurakatowase. Troubador. Baimipantao. Fenghuapantao. Hakubo. } \\
\text { Beni Hakuto. Zaofengwang. Xiacui. Yangzhouzaotiantao }\end{array}$ \\
\hline
\end{tabular}

Accessions containing 2 haplotypes were underlined.

In addition, 41-bp indels were also detected, including 2 main indels of 17 and 18 bp, two 2-bp (CC, TT), and two 1-bp (C, G) indels. Only one indel (G) was found in an exon region. By comparing each category of indels, a relative bias was observed for the $\mathrm{C}$ and $\mathrm{G}$ nucleotide indels but not the $\mathrm{A}$ and $\mathrm{T}$ nucleotide indels. The average indel frequency was one in every $195 \mathrm{bp}$. In addition to the indels, 3 CAPS primer sets were designed to contain indels within enzyme sites (Table 3). The CAPS analysis was performed on genomic DNA from 15 peach accessions with NMF (i.e., 'Troubador', 'Phillips', 'Jinxu', and 'Myojyo'), melting flesh (MF; i.e., 'Beijingyixianhong', 'Baopiyangtao', 'Xuebaitao', 'Fantasia', 'Galaxy', 'Okubo', 'Kurakatowase', 'Mayfire', and 'Baihuashuimi'), and "stony hard” (i.e., 'Yumyeoung' and 'Xiacui') phenotypes.

\begin{tabular}{|c|c|c|c|c|}
\hline Primer name & Primer sequence (forward and reverse) & $\begin{array}{l}\text { Restriction } \\
\text { endonuclease }\end{array}$ & PCR product size & Insertion-deletion/after digestion \\
\hline CAPS01 & $\begin{array}{l}\text { 5'-TTCCACCTAGAAGAGCCAATA-3' } \\
\text { 5'-AGCTACGATGAAGTCATTTTG-3' }\end{array}$ & HруCH4V & 259 & $19 / 140+119$ \\
\hline CAPS02 & $\begin{array}{l}\text { 5'-ATCAACATTATTGCCCCGACA-3' } \\
\text { 5'-CAAGGCTCGACCTTTGTAAGT-3' }\end{array}$ & MaeIII & 300 & $18 / 122+178$ \\
\hline CAPS03 & $\begin{array}{l}\text { 5'-GGTCAATGTCGAAAATCCTAT-3' } \\
\text { 5'-TTGGGTTTGCTTTGGGTCTAA-3' }\end{array}$ & MaeIII & 275 & $17 / 151+124$ \\
\hline
\end{tabular}

The amplification products were digested with restriction enzymes. Restriction products achieved with the primer CAPS01 ( $\mathrm{HpyCH} 4 \mathrm{~V})$ produced 2 bands with estimated sizes of $\sim 140$ and $119 \mathrm{bp}$, respectively (Figure 2; lanes 3 and 5), and the undigested DNA fragment produced a single band with an estimated length (Figure 2; lanes 2 and 4) in MF ('Troubador' and 'Phillips') accessions. Furthermore, primers CAPS02 and CAPS03 (MaeIII) had great reproducibility and polymorphisms were obtained, which can therefore be applied to further genotyping of the peach.

\section{Genetic relationship}

Based on Nei's genetic distance coefficient (Nei, 1972), a dendrogram was obtained using NJ cluster analysis. The 67 accessions were divided into 2 groups and 4 subgroups based on the genetic diversity of the endo- $P G$ gene (Figure 3). The main cluster "I" included the subgroups I-1 and I-2. Subgroup I-1 included 26 accessions - 10 accessions with NMF fruit phenotypes, presenting a mixed distribution with different adherence levels to the stone in the dendrogram. 


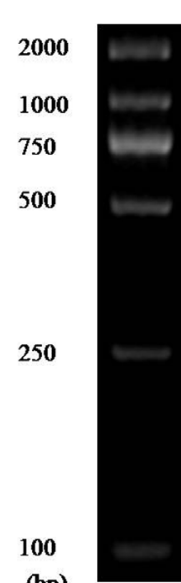

(bp)

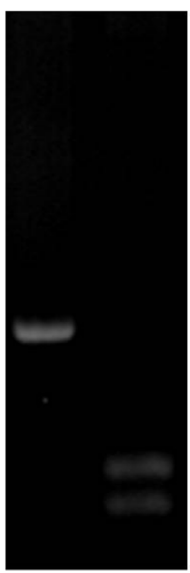

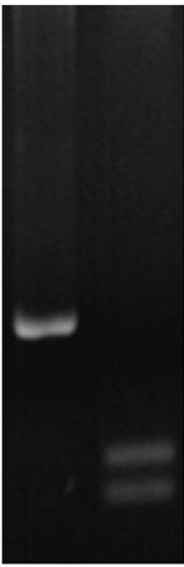

45

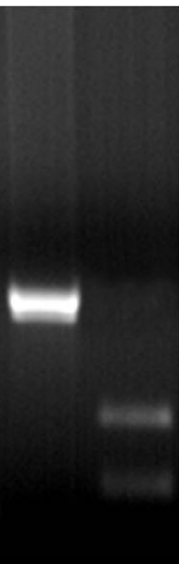

6

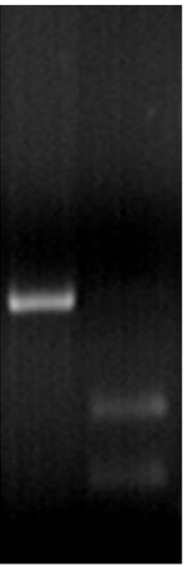

8

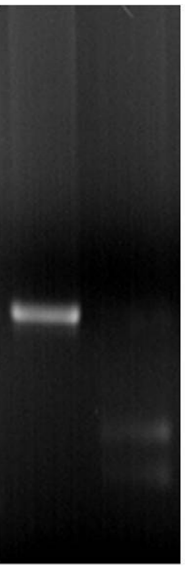

$10 \quad 11$

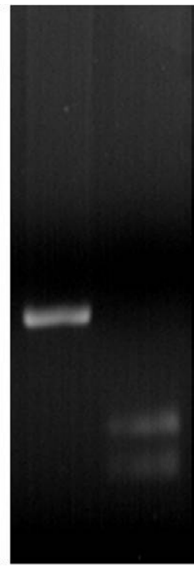

1213

Figure 2. Cleaved amplified polymorphic sequence (CAPS) restriction patterns of genomic DNA from the leaves of peach (Prunus persica) accessions with NMF ('Troubador', 'Phillips', 'Myojyo', and 'Jinxu') and MF ('Beijingyixianhong' and 'Mayfire') fruit phenotypes, obtained as described in the Material and Methods, were restricted with 3 primers (Table 3). Lane 1, 2-kb DNA ladder; lane 2, undigested endo-PG gene sequence from 'Troubador'; lane 3, CAPS01-digested endo- $P G$ gene fragments from 'Troubador'; lane 4, undigested endo$P G$ gene sequence 2 from 'Phillips'; lane 5, CAPS01-digested endo- $P G$ gene fragments from 'Phillips'; lane 6, undigested endo- $P G$ gene sequence from 'Beijingyixianhong'; lane 7, CAPS02-digested endo- $P G$ gene fragments from 'Beijingyixianhong'; lane 8, undigested endo- $P G$ gene sequence from 'Jinxu'; lane 9, CAPS02-digested endo- $P G$ gene fragments from 'Jinxu'; lane 10, undigested endo- $P G$ gene sequence from 'Myojyo'; lane 11, CAPS03-digested endo- $P G$ gene fragments from 'Myojyo'; lane 12, undigested endo- $P G$ gene sequence from 'Mayfire'; lane 13, CAPS03-digested endo- $P G$ gene fragments from 'Mayfire'.

Subgroup I-2 included 20 accessions; 4 were clingstone accessions, while the others exhibited freestone phenotypes. The main cluster "II" also included the subgroups II-1 and II-2. Subgroups II-1 included 12 accessions. Furthermore, the NMF accessions 'Yanwuhong' and 'Wuyuexianbiangan' were independently classified within this group, indicating a distant relationship from the other NMF accessions. Subgroup II-2 included 23 accessions, which were all clingstone phenotypes, with the exception of the accession 'Okubo'. Moreover, we found 2 indels ("CATAGTGTAACGTTTTTG" at positions 586-603; "TTCATTGTATGTG CAAT," at positions 798-814; Figure 1) unique to subgroup I-1; both were deletions in subgroup I-2. Moreover, the indel "TATAGTGTAACGTTTTTT" (positions 586-603; Figure 1) was unique to cluster "II". As an important note, both 'Yumyeoung' and 'Xiacui', with "stony hard" fleshes, were distributed within this same cluster, indicating that they have high genetic similarity to the endo- $P G$ gene.

\section{DISCUSSION}

\section{SNP markers for peach genotype identification}

In this study, 1174-bp DNA fragments of the endo- $P G$ gene were amplified from peach accessions with a slight variation from previous reports (i.e., $1172 \mathrm{bp}$ ). This variation was primarily caused by the 2 small indels of genetic variation (positions 949-950 and 1039-1040; Figure 1). 


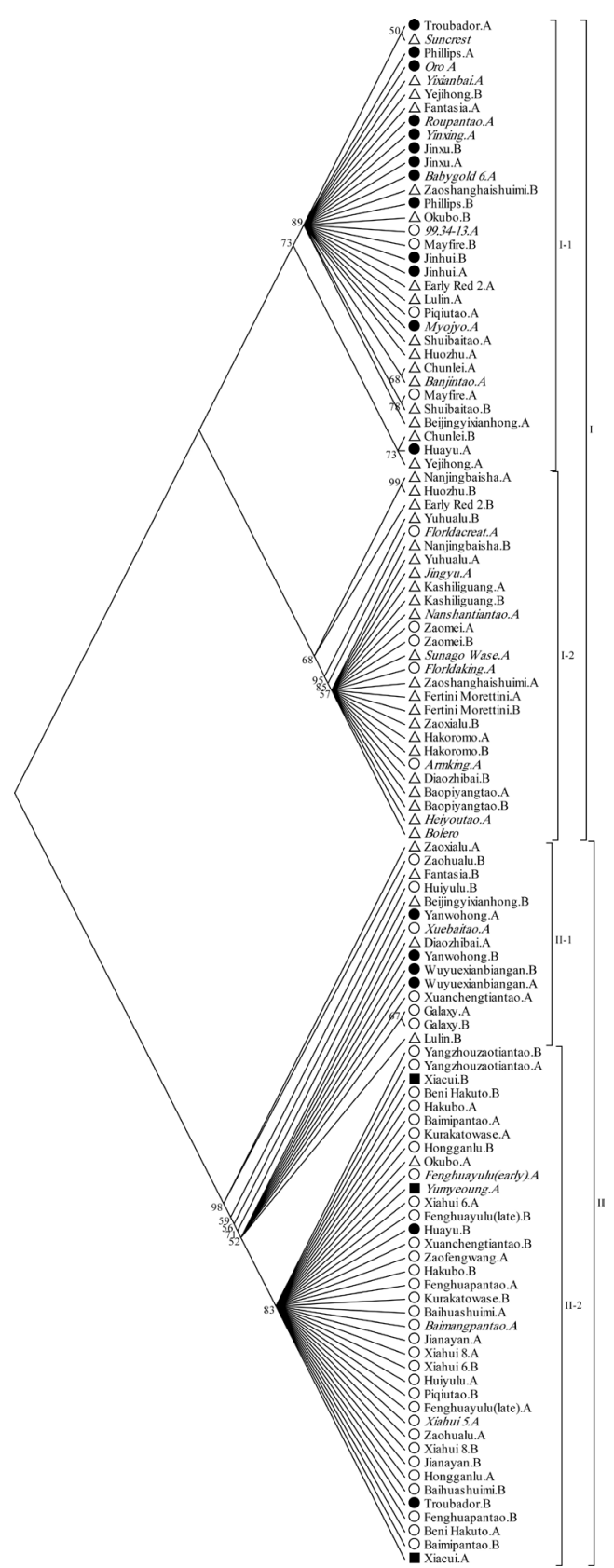

Figure 3. Dendrogram constructed with single nucleotide polymorphism (SNP) genotype data using the neighborjoining (NJ) clustering method. The numbers above the branches represent bootstrap values $>50$. The " $A$ " and " $B$ " following accession names indicate 2 different alleles in a single accession. The homozygote individuals, 'Oro A', 'Bolero', and 'Suncrest', which were downloaded from NCBI, are shown in italics. The symbols before the accessions codes indicate adherence to the stone, with triangles and circles representing freestone and clingstone cultivars, respectively. The symbols of the internal blackbodies indicate the NMF cultivars; the others are MF cultivars. The symbols with squares indicate "stony hard" cultivars. 
Meanwhile, the results revealed a significantly greater level of genetic diversity than the previous study, which showed that their fragment included only 58 SNPs and 6 indels (Morgutti et al., 2006). This is likely due to the smaller population size; the identified SNPs can be selected for developing markers for further study. As a result of the sequence comparisons between intron and exon regions, the highest level of sequence polymorphism was observed in the intron regions, clearly echoing previous research (Morgutti et al., 2006; Aranzana et al., 2012). This result strongly suggests a possible regulatory role of the intron regions in the expression of the endo- $P G$ gene. As expected, transition mutations were more common, and the numbers of SNPs were greater than those in other reports (Zhang et al., 2010; Fu et al., 2010; Aranzana et al., 2012), indicating that the endo- $P G$ gene has a high level of genetic diversity. Meanwhile, small indels (1-5 bp) were more numerous than large indels ( $>100 \mathrm{bp})$, which have been found to be highly infrequent in plants, suggesting that they may be slightly deleterious (Tenaillon et al., 2002). We should give top priority to the indels of 5-20 bp for designing new CAPS markers. The smaller size of these indels should facilitate CAPS performance and increase the efficacy of the process. Moreover, these smaller indels can be utilized as genetic markers available for scanning genetic diversity from large populations. Concurrently, we also used the AS (allele-specific) PCR method to assay previously identified SNPs (Jeong and Saghai Maroof, 2004; Hayashi et al., 2004). Unfortunately, the stability of the ASPCR primers was poor; we presumed that the type and dosages of the DNA polymerase had a significant effect on the success rate for AS-PCR. Further optimization of multiplex PCR is needed to evaluate its general applicability.

\section{Genetic diversity and utilization of the peach germplasm}

Throughout this study, we found that the MF could be divided into 3 types according to the texture of the fruit (Z.J. Shen, unpublished data), including soft, hard melting, and mealiness. However, we found that the accessions with the same fruit texture did not generally cluster together within the dendrogram (Figure 3). Thus, there is a much more complex mechanism of gene regulation influencing fruit texture.

In this study, subgroup II-2 contained 2 accessions 'Yumyeoung' and 'Xiacui', both containing "stony hard" flesh, which originated from Korea and the Jiangsu Province of China, respectively. As we understand it, "stony hard" is a flesh texture in peach that occurs in cultivars with a reduced level of ethylene production and was originally characterized by its crispy fruit flesh (Hayama et al., 2006a,b). The accessions 'Yanwohong' and 'Wuyuexianbiangan', containing the NMF genotype, were classified into cluster "II" and deviated from other NMFs of subgroup I-1. This is likely due to the more complicated textures found in these fruits; the moisture content was lower and the tenacious texture was greater than those of other NMF accessions, and therefore, were more similar to the stony hard peach.

Based on previous data, the $\mathrm{SNP} \mathrm{C}_{\mathrm{NMF}}$, at position 353 of the DNA fragments (Figure 1), was found in the MF cultivars 'Okubo' and 'Fantasia'; it was also present in the "stony hard" peach cultivars 'Xiacui' and 'Yumyeoung' (Morgutti et al., 2006). Significantly, we observed that these accessions were not classified into subgroup I-1 with the other NMF accessions; rather, they were distributed within subgroup II-2 along with the MF accessions on the dendrogram. This likely means that the "stony hard" peach has a relatively close relationship with the MF accessions when compared to the other NMF cultivars. A representative cultivar 'Xiacui', selected and bred by a member of our team, has an abundant sugar accumulation and 
maintains its fruit hardness for 20 days postharvest in our preliminary study (Y. Yang, unpublished data). This cultivar has higher potential for development and utilization in the future.

This study also provides strong evidence that NMF and clingstone localize to the same locus, although it is unclear whether the same gene or different copies of the endo- $P G$ gene within the locus controls the 2 traits. Generally, accessions with the same texture or adherence levels of the ripe fruit fell within the same group or subgroup, indicating their availability to be classified into the major phenotypes of freestone MF, clingstone MF, and clingstone NMF. These data agree with a previous report (Peace et al., 2005). In conclusion, the present study provides compelling evidence demonstrating that SNPs have the potential to be used: 1) as genetic markers for rapid and effective genotyping, 2) in marker-assisted breeding and positional cloning, and 3) in genome-wide association studies.

\section{ACKNOWLEDGMENTS}

We would like to thank Rangjin Xie for his excellent technical assistance and advice, Zhijun Shen and Chunhua Zhang for their comments on the manuscript, and the China Agriculture Research System (\#CAR-31) for their financial support.

\section{REFERENCES}

Aranzana MJ, Illa E, Howad W and Arus P (2012). A first insight into peach [Prunus persica (L.) Batsch] SNP variability. Tree Genet. Genome 8: 1359-1369.

Brummell DA, Dal Cin V, Crisosto CH and Labavitch JM (2004). Cell wall metabolism during maturation, ripening and senescence of peach fruit. J. Exp. Bot. 55: 2029-2039.

Eduardo I, Chietera G, Pirona R, Pacheco I, et al. (2013). Genetic dissection of aroma volatile compounds from the essential oil of peach fruit: QTL analysis and identification of candidate genes using dense SNP maps. Tree Genet. Genome 9: 189-204.

Emanuelli F, Lorenzi S, Grzeskowiak L, Catalano V, et al. (2013). Genetic diversity and population structure assessed by SSR and SNP markers in a large germplasm collection of grape. BMC Plant Biol. 13: 39.

Fischer RL and Bennett A (1991). Role of cell wall hydrolases in fruit ripening. Ann. Rev. Plant Biol. 42: 675-703.

Fu Z, Yan J, Zheng Y, Warburton M, et al. (2010). Nucleotide diversity and molecular evolution of the PSY1 gene in Zea mays compared to some other grass species. Theor. Appl. Genet. 120: 709-720.

Hayama H, Ito A, Moriguchi T and Kashimura Y (2003). Identification of a new expansion gene closely associated with peach fruit softening. Postharvest Biol. Technol. 29: 1-10.

Hayama H, Shimada T, Fujii H, Ito A, et al. (2006a). Ethylene-regulation of fruit softening and softening-related genes in peach. J. Exp. Bot. 57: 4071-4077.

Hayama H, Tatsuki M, Ito A and Kashimura Y (2006b). Ethylene and fruit softening in the stony hard mutation in peach. Postharvest Biol. Technol. 41: 16-21.

Hayashi K, Hashimoto N, Daigen M and Ashikawa I (2004). Development of PCR-based SNP markers for rice blast resistance genes at the Piz locus. Theor. Appl. Genet. 108: 1212-1220.

Jeong SC and Saghai Maroof MA (2004). Detection and genotyping of SNPs tightly linked to two disease resistance loci, Rsv1 and Rsv3, of soybean. Plant Breed. 123: 305-310.

Komori T and Nitta N (2005). Utilization of the CAPS/dCAPS method to convert rice SNPs into PCR-based markers. Breed. Sci. 55: 93-98.

Konieczny A and Ausubel FM (1993). A procedure for mapping Arabidopsis mutations using co-dominant ecotypespecific PCR-based markers. Plant J. 4: 403-410.

Lester DR, Speirs J, Orr G and Brady CJ (1994). Peach (Prunus persica) endopolygalacturonase cDNA isolation and mRNA analysis in melting and nonmelting peach cultivars. Plant Physiol. 105: 225-231.

Ma QH, Wang LM, Song YR and Zhu ZQ (1999). Cloning and expression of a cDNA encoding endopolygalacturonase from Feicheng peach (Prunus persica). Acta Bot. Sin. 41: 263-267.

Manubens A, Lobos S, Jadue Y, Toro M, et al. (1999). DNA isolation and AFLP fingerprinting of nectarine and peach varieties (Prunus persica). Plant Mol. Biol. Rep. 17: 255-267. 
Martinez-Garcia PJ, Parfitt DE, Ogundiwin EA, Fass J, et al. (2013). High density SNP mapping and QTL analysis for fruit quality characteristics in peach (Prunus persica L.). Tree Genet. Genome 9: 19-36.

Morgutti S, Negrini N, Nocito FF, Ghiani A, et al. (2006). Changes in endopolygalacturonase levels and characterization of a putative endo- $P G$ gene during fruit softening in peach genotypes with nonmelting and melting flesh fruit phenotypes. New Phytol. 171: 315-328.

Nei M (1972). Genetic Distance between Populations. Am. Nat. 106: 283-292.

Peace CP, Crisosto CH and Gradziel TM (2005). Endopolygalacturonase: a candidate gene for freestone and melting flesh in peach. Mol. Breed. 16: 21-31.

Tamura K, Peterson D, Peterson N, Stecher G, et al. (2011). MEGA5: molecular evolutionary genetics analysis using maximum likelihood, evolutionary distance, and maximum parsimony methods. Mol. Biol. Evol. 28: 2731-2739.

Tatsuki M, Nakajima N, Fujii H, Shimada T, et al. (2013). Increased levels of IAA are required for system 2 ethylene synthesis causing fruit softening in peach (Prunus persica L. Batsch). J. Exp. Bot. 64: 1049-1059.

Tenaillon MI, Sawkins MC, Anderson LK, Stack SM, et al. (2002). Patterns of diversity and recombination along chromosome 1 of maize (Zea mays ssp. mays L.). Genetics 162: 1401-1413.

Verde I, Bassil N, Scalabrin S, Gilmore B, et al. (2012). Development and evaluation of a 9K SNP Array for peach by internationally coordinated SNP detection and validation in breeding germplasm. PloS One 7: e35668.

Zhang D, Yang X, Zhang Z and Li B (2010). Expression and nucleotide diversity of the poplar COBL gene. Tree Genet. Genome 6: 331-344. 